\title{
MITO E SOCIEDADE NA LITERATURA LATINO- AMERICANA: NERUDA, CARPENTIER, BOLAÑO
}

\author{
Pedro Dolabela Chagas
}

Resumo: Discussão sobre a problemática identitária na literatura latino-americana: a sua associação oitocentista à representação da natureza e da paisagem social; a sua longa duração entre os séculos XIX e XX; a sua politização pela dicotomia entre a América Latina e o Centro representado pela Europa e pelos EUA. A construção da identidade como produção de mitos: como construção de passados úteis, valoração positiva ou negativa do presente, projeção de futuros possíveis. A presença do mito em Canto geral, de Pablo Neruda; a sua recusa em 2666, de Roberto Bolaño; discussão sobre as razões desta recusa: a concentração no presente em detrimento da projeção do futuro. Localização de um tensionamento embrionário do mito identitário em $O s$ passos perdidos, de Alejo Carpentier: discussão sobre os termos de orientação deste tensionamento e a diferença que ele produzia em relação à história anterior do romance latino-americano. Sugestão do fechamento recente da época histórica dominada pela problemática identitária na narrativa latino-americana.

Palavras-chave: Pablo Neruda; Alejo Carpentier; Roberto Bolaño; Romance Latino-Americano; Mito e Identidade.

Abstract: The problematic of identity representation in LatinAmerican literature: its $19^{\text {th }}$ Century association to the representation of nature and the social landscape; its long duration in the $19^{\text {th }}$ and $20^{\text {th }}$ Centuries; its politicization through the dichotomy between Latin America and a Center represented

* Universidade Estadual do Sudoeste da Bahia. 
by Europe and the USA. Identity construction as a production of myths: as a construction of usable pasts, as a positive or negative evaluation of the present, as a projection of possible futures. The presence of myth in Pablo Neruda's Canto general; its rejection in Roberto Bolaño's 2666; the possible reasons of this rejection: a concentration in the present in detriment of the future. Location of an embrionary tensioning of the identity myths already in Alejo Carpentier's The lost steps: discussion of the guiding terms of that tensioning and the difference it produced in the history of the Latin-American novel. Suggestion of the recent closure of the historical epoch dominated by the problematic of identity in the Latin-American novel.

Keywords: Pablo Neruda; Alejo Carpentier; Roberto Bolaño; Latin-American Novel; Myth and Identity.

No processo de fundação das literaturas nacionais da América Latina recém-independente, no século XIX, a representação da natureza e da paisagem social foi, como é sabido, ${ }^{1}$ posta a serviço da pesquisa identitária. Na poesia e no romance, os mitos de origem, a equalização dos problemas atuais, a construção de "passados úteis" e a projeção de futuros possíveis foram entrelaçados à projeção das identidades locais sobre a natureza e a paisagem social circundante - procedimento que, especialmente no romance, seguiria dominante em boa parte do século seguinte. ${ }^{2}$ Tais literaturas eram imbuídas de pretensões à verdade, mesmo quando colocadas pelo filtro da subjetivação autoral, que, a rigor, deveria obrigar o observador a reconhecer-se limitado à própria observação e, desse modo, apartado da imanência do objeto observado: esta cisão foi conciliada, no romantismo, pela admissão da experiência sensível como modo de acesso imediato à realidade exterior, cuja apresentação combinaria o registro factual com a

\footnotetext{
${ }^{1}$ Cf. ECHEVARRÍA, 2000; MARTIN, 1989, 2006; SOMMER, 2004. Para o caso brasileiro, v. LIMA, 1983; SÜSSEKIND, 1984; ROUANET, 1991.

${ }^{2}$ Cf. ECHEVARRÍA, 2000; MARTIN, 1989; SÜSSEKIND, 1984.
} 
impressão do lugar sobre a sensibilidade do observador. Como forma de simbolização da identidade, a representação da paisagem admitia, portanto, a oscilação entre o registro objetivo e a impressão pessoal: em sua longa permanência temática na literatura latinoamericana dos séculos XIX e XX, a paisagem natural e social era o substrato "concreto" tomado como metonímia da identidade de regiões, nações, ou do continente como um todo.

Esta permanência foi possibilitada pela flexibilidade apresentada pela representação da physis como representação da identidade. Em sua forte produção de reconhecimento no leitorado, com o passar do tempo ela facilmente agregaria a "cultura" e a "história" à sua matriz descritiva, explicativa e interpretativa das condições sociais e políticas, permitindo que padrões de representação fossem substituídos sobre uma base de permanência, i.e.: sem que a própria associação entre paisagem e identidade fosse questionada. Nestes termos, se Os passos perdidos, de Alejo Carpentier, se diferenciava dos modos predominantes de representação ficcional da América Latina, era porque aquele romance trazia um narrador que observava o lugar a partir de uma posição culturalmente exógena a ele, mostrando-se incapaz de apreender o seu sentido. Isso era trocar a onisciência e o "retratismo" por um olhar culturalmente deslocado, permanentemente defasado em seu esforço de apreensão da diferença - o que colocava em suspenso, afinal, a remissão à identidade pela apresentação da paisagem, num tensionamento da projeção dos mitos identitários que, historicamente, haviam sido responsáveis, na ficção latinoamericana, pelo equacionamento ou pela crítica das tensões sociais sob conceitos compartilhados.

Carregados valorativamente e mediados pelas questões urgentes do tempo, permeados pela expressão ideológica e pela análise social, era comum que os mitos revolvessem a dicotomia entre a natureza e a cultura autóctone, de um lado, e a civilização e a modernidade, de outro, delineando a interpretação do continente como outro em relação aos modelos propagados por um Centro (europeu e, mais tarde, norte-americano) dos quais as 
metrópoles latino-americanas passaram, a certa altura, a figurar como variações locais (como reproduções locais dos vetores modernizadores do Centro, em contraste com as regiões dominadas pela cultura autóctone). Particularmente entre meados do século XIX e a primeira metade do século XX, esta dicotomia orientaria o olhar latino-americano sobre o próprio continente: mirar-se no Centro era autoconferir-se um lugar no mundo, o que receberia implicações diferentes ao longo do tempo - da conotação crítica que acusava a medida do nosso atraso, ao valor-verdade da nossa cultura diante da "abstração", do "pragmatismo" ou da "artificialidade" das culturas centrais, oposições que ecoavam a posição frágil da América Latina no sistema-mundo. Pois a comparação com o Centro problematizava, implícita ou explicitamente, o status específico da nossa modernidade: seríamos já modernos, ainda não plenamente modernos ou condenados a uma caricatura da modernidade, cuja reversão estaria eternamente adiada? Em 1864, um intelectual boliviano perguntava:

"Os povos merecem sua sorte", disse Montesquieu. Para a Hispano-América, são estas palavras uma condenação definitiva do passado, uma ameaça tremenda ao presente, ou um prognóstico fagueiro sobre o porvir?

- No seio da democracia vossa impotência é radical, nos gritam do Velho Mundo.

-A noite será longa e tristíssima, dizem alguns filhos do Novo.

- Hosana! Porque os tempos se aproximam, clamam outros com entusiasmo.

Qual é a verdade? (RENÉ-MORENO, 2011, p. 213)

Penetrando o século XX, esta inquietação iria predominar enquanto a modernização do continente se colocou como objeto de anseio, de frustração e de angústia - mas o que ocorre quando se passa a estimar que, mesmo com seus sucessos e fracassos, a América Latina já se tornou inapelavelmente moderna? O que acontece, hoje, quando a modernidade chega ao presente quando se compreende que ela já está aí, mesmo que ela não 
tenha recebido qualquer formatação ideal? Por muito tempo esta percepção não se impôs com clareza, parecendo que o futuro do continente estava totalmente em aberto. O futuro era tomado, então, como objeto de planejamento e disputa, na sugestão de "caminhos", "metas" ou "planos" que prometessem a integração aos modelos institucionais e econômicos do Centro (que incorporaria Moscou como opção paralela). Mas o que ocorre, no campo literário, quando esta percepção se esvanece e o cotejo do presente passa a predominar sobre a projeção do futuro? $\mathrm{O}$ futuro decerto não desaparece do horizonte: comparativamente, é a sua extensão, o seu raio de cobertura que se reduz a um futuro curto, abrindo espaço para que o presente que se alargue como foco de atenção. ${ }^{3}$ Durante muito tempo a literatura repercutiu as dicotomias que tomavam o Centro como um modelo distante, a ser alcançado nalgum momento imaginado; quando a modernização chega ao presente, deixa-se de comparar a atualidade com modelos imaginados de futuro para compreendê-la como uma realidade em si mesma, mesmo que para defini-la como uma versão corrompida - mas já realizada, em todo caso-daqueles modelos. Conforme veremos, a literatura responderá a esta nova sensibilidade social, distanciando-se da literatura passada e assim sensibilizando a historiografia para a identificação, no passado, dos momentos iniciais de emergência destas novas relações entre a literatura, a sociedade e os mitos identitários latino-americanos: compreender a função inicial do mito identitário e a mitigação atual da sua produção, para então observar a emergência desta quebra em Carpentier, é o objetivo geral deste artigo.

Para tanto, posicionaremos Os passos perdidos entre Canto geral, de Pablo Neruda, e 2666, de Roberto Bolaño. Esta disposição nos levará da reafirmação dos mitos norteadores da dicotomia Sul-Centro - em Neruda - à sua aparente dissolução em Bolaño, já no século XXI. Entre um momento e outro, veremos

${ }^{3}$ Conforme desenvolvido em GUMBRECHT, 2010. 
como, em Carpentier, a dicotomia ainda remetia à possibilidade de uma conciliação imaginada da América Latina consigo mesma (através do mito), mas sem que ela de fato conseguisse estabilizar retoricamente a identidade do continente - e ao não receber um fechamento real, a conciliação identitária se tornava um problema em aberto, insinuando-se o seu fundamento mítico e, com isso, fragilizando-a como modo de conhecimento real do continente. Em contraste, Neruda ainda insistia na manipulação dicotômica dos mitos, ao passo que Bolaño, décadas mais tarde, simplesmente deixaria de apelar a eles, num sintoma provável da emergência de uma nova autopercepção: teria a América Latina finalmente alcançado uma posição no sistema-mundo que a leva a definir-se como o agente principal da sua própria história, para o bem ou para o mal? Teria a imaginação latino-americana assumido plena responsabilidade pela sua própria construção societária, deixando de identificar as ações do Centro como modelos a serem seguidos ou como causas externas, mais ou menos decisivas, das suas condições internas? Talvez seja cedo para apostar nesta explicação - mas já é possível, em todo caso, situar a emergência, no romance contemporâneo, de uma nova sensibilidade para a ficcionalização da realidade social latino-americana: a partir da discussão dos seus termos gerais de orientação (com a qual iniciaremos nosso argumento), localizaremos, em Carpentier, as condições embrionárias do seu surgimento.

\section{Neruda, Bolaño}

Observar o próprio lugar com um olhar de estrangeiro, esta posição aporética do narrador latino-americano muitas vezes facilitou a conciliação das limitações atuais com a utopia imaginada pelo romancista. É o que Doris Sommer (2004) identifica nas "ficções de fundação" do século XIX (Iracema, entre elas), em que as diferenças raciais e de desenvolvimento regional - potencialmente desestabilizadoras da unificação nacional - eram equacionadas 
(com maior ou menor completude) em soluções de compromisso simbolizadas pelo enlace amoroso entre personagens representativos de grupos sociais diferentes. $O$ recurso ao enredo romântico, de apelo tão popular, favorecia a síntese da complexidade local através do mito - através da união do diverso sob uma identidade comum, sob símbolos compartilhados cuja legitimidade (moral ou política) e apelo afetivo fossem potencialmente amplos.

Bem entrado o século XX, tal remissão a uma simbologia de ampla aceitação potencial ainda era observada na poetização do Orinoco por Pablo Neruda - na sua politização da paisagem como metáfora da identidade. Mais do que demarcar fisicamente a sua singularidade, em Neruda a natureza encarnava a potência própria do novo mundo: a sua força ancestral, telúrica, o seu reservatório de energia que o próprio continente ignorava, a sua fonte de vitalidade que ele ainda não soubera reconhecer e que, em Canto General, sugeria uma possibilidade de futuro no qual a América Latina, tomando posse de si mesma, afirmaria sua própria voz. Mobilizada, em Neruda, para a diferenciação política futura, a natureza não aparecia exatamente como physis, mas como elegia da força que o eu experienciava em seu impacto - num choque de intensidade que, no poema, era mobilizado retoricamente por uma ideologia anti-sistêmica que havia sido rara nas letras latinoamericanas do século XIX, mas que agora, no século que rotinizaria a interpretação da América Latina como um satélite de um sistema global de "dominação", revelava-se uma versão atualizada do mito:

Orinoco, déjame em tus márgenes de aquella hora sin hora:

déjame como entonces ir desnudo; entrar en tus tinieblas bautismales.

Orinoco de agua escarlata, déjame hundir las manos que regresan a tu maternidad, a tu transcurso, río de razas, patria de raíces, tu ancho rumor, tu lámina salvaje viene de donde vengo, de las pobres 
y altivas soledades, de um secreto

como una sangre, de una silenciosa

madre de arcilla. (NERUDA, 1996, p. 16)

$\mathrm{Nu}$, o eu pede entrada no rio-mãe. Pode-se argumentar que esta subjetivação da natureza - a comunhão do eu com a natureza - substituía o equilíbrio entre o pertencimento e a distância (do observador à realidade observada) pela total dissolução do eu no lugar. Mas permeia estes versos uma valência política peculiar; se Neruda se inspirava em Whitman, como é frequentemente apontado, ${ }^{4}$ havia entre o poeta latino-americano e o seu antecessor norte-americano uma diferença política fundamental: ao cobrir democraticamente a diversidade da experiência da América do Norte, Folbas de relva irmanava o eu lírico a uma multiplicidade de indivíduos, lugares, paisagens e profissões que, sob o seu olhar, passavam a formar, em sua variedade intrínseca, um único conjunto dentro do qual o eu se afirmava, mas ao qual ele não se sobrepunha. O efeito retórico de Whitman projetava o eu não como "diretor" da matéria poetizada, mas como um observador colocado no mesmo plano do tecido social ao qual ele pertencia - ainda que o conjunto social se constituísse como tal, dentro do poema, apenas através da sua voz. Mas esta é uma ambiguidade própria à democracia: apenas a declaração da igualdade cria condições para a sua afirmação prática. É inerente à constituição da coletividade democrática, então, a rasura das individualidades que estabeleceram os termos de constituição da igualdade e da liberdade individual - sob o risco de se destacá-las e sobrepô-las à coletividade à qual elas devem pertencer como iguais. É assim que, em Whitman, a assimetria entre o pertencimento e a distância, apesar de visível analiticamente, era rasurada performativamente: o eu observa de fora uma realidade da qual ele não se distancia, construindo, paradoxal mas

${ }^{4}$ Por exemplo em BLOOM, 1995. 
persuasivamente, uma visão ao mesmo tempo onisciente (externa) e integradora (interna) de uma totalidade intrinsecamente múltipla. Isso em nada se assemelha ao encontro, em Neruda, do eu com uma América da qual ele não era íntimo - a ponto de pedir-lhe aceitação e pertencimento. $\mathrm{Na}$ América democrática de Whitman, a sociedade prevalece sobre a natureza, predominando o dado material e humano: pessoas, objetos e profissões despontam num construto retórico que integrava o eu ao lugar, e cuja persuasão era também legitimada pelo mito, ainda que este fosse um mito bem diferente do seu congênere latino-americano - era o mito democrático que se apoiava nos "ideais fundadores" do país, a descrição positiva do seu presente e o otimismo quanto ao seu futuro, convergindo a diacronia e a sincronia numa totalidade dinâmica e complexa, mas ainda assim integralizável num domínio comum:

Grande a liberdade! Grande a igualdade! Sou seu seguidor, Piloto das nações, escolha seu navio .... velejo onde você veleja, Seus músculos são os da vida e os da morte .... a ciência perfeita .... tenho fé absoluta em você. (WHITMAN, 2006, p. 205)

Enquanto isso, o poema do Sul postava-se em meio a ordem autocrática a ser combatida, mostrando um enunciador solitário que, privado do amparo em forças políticas e sociais confiáveis, conferia autoridade a si mesmo para atribuir à realidade o seu justo valor, com isso jamais anulando - como em Folbas de relva - o seu posicionamento pessoal. Enquanto o eu de Whitman afirmava performativamente não a si mesmo, mas a sua sociedade de origem, Neruda se afirmava como observador ao lançar a um futuro incerto a correção de uma história que desviara a América do Sul da sua potência original - que, mitigada na realidade atual, se mostrava intacta na natureza: o Orinoco de Neruda revelava a grandeza original do continente, obscurecida pela violência do seu empurrão involuntário à modernidade. Se nem o presente nem o passado imediato permitiam a imaginação de um futuro satisfatório, Neruda retomava o phármakon identitário ao tratar a 
América Latina como um poema, pensando-a como uma matéria, um conteúdo (físico, antropológico) ainda por receber uma expressão formal (interpretativa, institucional) adequada. Força telúrica ainda desprovida de tradução à altura, a Conquista teria sufocado a sua grandeza e condenado o continente a uma relação assimétrica com o Centro: paralelo ao mito da natureza, corre, em Neruda, o mito histórico da destruição de uma harmonia primeva:

Los hijos de la arcilla vieron rota

su sonrisa, golpeada

su frágil estatura de venados,

y aún en la muerte no entendían. (NERUDA, 1996, p. 45)

Diante da corrupção atual, apenas um passado mitificado, muito recuado no tempo, poderia servir de fundamento identitário assimilável à imaginação do futuro - mas hoje, passadas tantas décadas, esta posição de Neruda parece distante. É difícil apontar o momento exato em que aqueles mitos perderam credibilidade; já nalguns romances do boom da literatura latino-americana, nos anos 60, é possível identificar uma abordagem meta-crítica da problemática identitária que revelava a sua compreensão como construção. Se mitos são inevitáveis - se toda representação da realidade social, cultural, histórica e linguística envolve a criação de mitos -, certa literatura do boom enfrentou a questão multiplicando pontos de vista, enredando a passagem do tempo, complexificando o juízo das ações, pluralizando as singularidades locais: várias Américas Latinas eram sobrepostas numa mesma obra, e toda simplificação era afastada. Era o que Cortázar teorizava em O jogo da amarelinha: o romancista como manipulador de códigos e construtor de realidades, tipo de teorização que fora rara nas gerações anteriores; mais tarde, em Yo el supremo, de Roa Bastos, a literatura viria a ser pensada como discurso, problematizando-se a relação entre escritura e verdade e entrevendo-se os limites do romance como representação da experiência histórica - o que era o máximo de autorreflexividade possível dentro do paradigma identitário. 
Seja qual for a genelogia, hoje fica claro que a ficcionalização da sociedade latino-americana se alterou profundamente. Um autor central como Roberto Bolaño ignoraria os termos da dicotomia atuante em Neruda, ao ignorar o olhar simultaneamente interno e externo que sintetizava a identidade local ao contrapôla explícita ou implicitamente ao Centro, o grande Outro. Em Bolaño, além disso, conciliações inexistem: a visão da paisagem não provoca um recuo no tempo recuperador de uma originalidade prémoderna; pelo contrário, penetra-se na realidade inapelavelmente moderna que a América Latina construiu para si. Durante muito tempo a dicotomia entre o pertencimento e a distância se apoiou no juízo sobre o lugar do continente na modernidade - sobre o seu status ainda-não-moderno, sobre a sua modernidade incompleta, sobre a sua condição de passado ou futuro do sistemamundo, noções que foram operatórias numa América Latina cujo futuro parecia em aberto. Mas em Bolaño o continente é irreversivelmente moderno: nossa modernidade é aquilo que vemos diante de nós. O continente se defronta com o seu demônio interno: este é o tom que predomina quando, em 2666, o feminicídio no México é ficcionalizado como rotina. Numa paisagem moderna, com suas lojas, fábricas, hotéis, subúrbios, bares e automóveis passando, os corpos das vítimas vão aparecendo, um após o outro, numa sucessão infinita:

Em meados de novembro, Andrea Pacheco Martínez, de treze anos, foi raptada ao sair da escola técnica secundária 16. [...] Quando a encontraram, dois dias depois, seu corpo mostrava sinais inequívocos de morte por estrangulamento, com ruptura da hioide. Tinha sido violentada anal e vaginalmente. Os pulsos apresentavam tumefações típicas de amarradura. Os tornozelos também estavam lacerados, com o que se deduziu que também tivera os pés amarrados. (BOLAÑO, 2010, p. 378-379)

A neutralidade do tom e a terminologia legista verticalizam a indiferença (do corpo político e dos formadores de opinião) pela 
repetição de crimes que não são solucionados, ou sequer investigados. Nada é mitificado nesta América Latina, tampouco sugerindo-se a violência como símbolo identitário contraposto. A condenação da atualidade não se apóia em qualquer hermenêutica segura; pelo contrário, há uma sensação de vazio interpretativo: inexplicado, o feminicídio não fornece uma interpretação que possa amparar a síntese identitária. O Centro (o Outro) não aparece como ponto de estabilização crítica (positiva ou negativa), assim como tampouco a realidade ficcionalizada se vincula a qualquer origem histórica discernível: nenhum passado é resgatado para a interpretação do presente, que, não sendo explicado historicamente, não recebe uma perspectiva de clausura, sendo lançado a uma duração indefinida. Ao que se soma a aproximação, operada em 2666, entre o horror mexicano e o horror do nazismo: colocado neste plano comum, o horror latino-americano perde algo da sua especificidade, generalizando-se como uma manifestação contextual da "banalidade do mal" - do horror impessoal, sistêmico, rotinizado, e tão notoriamente recorrente, ao redor do mundo, no século passado. Se Jorge Volpi ${ }^{5}$ trata Bolaño como o "último escritor latino-americano", é porque ele teria se comportado como "latino-americano" para consumar a própria perda de significado do termo "América Latina" como promessa de síntese identitária de um continente que, hoje, não mais se reconhece como unitário. A sua unidade subsiste apenas na imaginação daqueles que ainda insistem em sobrepor a ideologia à observação empírica da sua realidade cotidiana: a época em que o continente foi unificado pelo "exotismo" (da sua cultura, das suas raças, da sua natureza) ou então, com sinais negativos, pelo seu "atraso" (sócio-econômico, civilizacional e político), aquela época cedeu passagem à pragmática de uma integração continental pautada pelas platitudes da diplomacia e pelo pragmatismo econômico - que ignoram as reivindicações, outrora

\footnotetext{
${ }^{5} \mathrm{~V}$. referência bibliográfica.
} 
ecoadas pela literatura, do seu "anticartesianismo" ou "encantamento"6 como características próprias à sua experiência cotidiana, proposição que, como no célebre "realismo mágico", procurava conciliar o exotismo com a reivindicação de um lugar digno para a América Latina dentro na política global. Durante algum tempo a conciliação do exotismo com o clamor pela autonomia política prorrogou o mito da unidade cultural, mas hoje o termo "América Latina" pouco expressa a autointerpretação de lugares e indivíduos que se sentem peruanos, argentinos, panamenhos, cubanos, mas não "latino-americanos". Apenas no exterior a unificação identitária parece preservar o seu significado simbólico, e isso é curioso: o termo "América Latina" operado como homogeneização produzida pelo outro, e não como uma ideologia internamente latinoamericana produzida pela comparação com o outro. A inversão é total: outrora, a observação do Outro suscitava nos ideólogos latino-americanos - Rodó, Martí, Vasconcellos, Ureña, Zea, Paz, Galeano... - o senso de unidade cultural interna; hoje, ao lado da indelével retórica de esquerda, é a observação feita pelo Outro que engendra uma unidade produzida para o consumo externo.

Daí que Volpi acene com a conclusão lógica pela qual, se a "América Latina" não mais existe, não há mais literatura propriamente "latino-americana". Figuras públicas como Vargas Llosa e Eduardo Galeano seriam os últimos intelectuais de fato "latino-americanos", uma vez que, quando falam os jovens escritores, não fala mais a América Latina (como em Neruda, Fuentes, García Márquez...), e nem mesmo o Peru, a Argentina ou o Chile: fala um peruano, um argentino, um chileno... Tendo pertencido à geração que abandonou progressivamente o engajamento político, mas que chegou a viver o autoritarismo em primeira mão, Bolaño teria ocupado uma posição historicamente privilegiada para questionar a idealização da identidade comum,

\footnotetext{
${ }^{6}$ Referimo-nos, neste artigo, à acepção weberiana do termo "desencantamento", do qual tomamos "encantamento" como antônimo perfeito.
} 
que, em sua juventude, ainda vigorara nas utopias de esquerda inspiradas pela revolução cubana. Mas os traumas geracionais provocados pela ditadura chilena, à direita, e pela decepção com a direção dada ao experimento cubano, à esquerda do espectro político, explicariam a sua recusa ao engajamento e o seu consequente ceticismo em relação à síntese identitária, explicando o sucesso de Bolaño entre jovens escritores cuja literatura, mesmo quando encharcada da temática local, não soa latino-americana: unificada pelo mercado editorial global, desapareceu dela o "ar de família" que a crítica identificara nas gerações anteriores.

\section{Carpentier}

É uma nova relação entre literatura e sociedade, portanto, que se fazia visível na obra - 2666 - que solapava os mitos identitários ao complexificar a sua ficcionalização da paisagem física e social da América Latina: retrospectivamente, podemos localizar uma manifestação inicial deste direcionamento em $O s$ passos perdidos, de Alejo Carpentier, publicado apenas três anos após Canto geral. Contemporâneo de Neruda, mas à diferença dele, Carpentier não fazia da elisão do tempo - o recuo a uma natureza atemporal e a um passado imemorial - um meio de identificação da potência própria do continente. Uma dinâmica bastante diferente surgia, em seu romance, quando o continente era penetrado em sua condição atual, na fragmentação produzida pela sua modernização: no contato direto com a diferença nenhum mito era facilmente invocado, pois mostrava-se difícil sobrepor à fragmentação uma síntese que anulasse a experiência do seu enfrentamento. Sob o olhar daquele que vivenciava diretamente a fragmentação, o lugar não era unificável sob um conceito comum, e a fragmentação se impunha em seus próprios termos: sem o amparo do mito, o observador devia depreender da realidade ao redor os termos pelos quais ela pedia para ser conhecida - mas estaria ele à altura do desafio? Enquanto Neruda conferia ao 
encontro com o lugar um equacionamento político estável, em Carpentier via-se o aprendizado dialógico de um observador que descobria lugares cuja complexidade ele era incapaz de enquadrar em qualquer interpretação segura; despreparado para lidar com aquilo que encontra, ela necessitava de tempo para a imersão - o que era bem diferente do posicionar-se perante o lugar para vivenciá-lo intimamente, como na experiência de simultâneo pertencimento e distância encenada por Neruda.

Em Os passos perdidos, um etnomusicólogo sulamericano, há muito radicado nos EUA, vem à América do Sul em busca de um artefato, de interesse antropológico mas ainda de utilização corrente, que poderia corroborar certa tese sobre a origem da música - implicando localizar no continente a presença viva de um domínio cultural ancestral, desaparecido noutras partes do mundo mas ainda subsistente, aqui, em meio a um território vasto e apenas parcialmente modernizado, porquanto integrado a nações que o território pouco reconhece. Há muito distanciado das suas origens, o narrador deve redescobrir o país: mesmo que muitas lembranças o acometam, os padrões culturais devem ser reaprendidos. Ao longo da sua estadia ele visita quatro diferentes lugares, quatro arquétipos diferentes da cidade latino-americana: iniciando pela cidade grande - centro da atividade política, de infraestrutura e paisagem modernas -, ele passa a uma vila pitoresca em meio à natureza, a uma cidade de fronteira na margem do grande rio, até se deparar com uma cidade recém-fundada, no alto do rio, por alguém que ele há pouco conhecera. A sucessão destes lugares demarca a "simultaneidade do não-simultâneo": ${ }^{7}$ eles mostram a coexistência, no presente, de quatro momentos históricos diferentes da América Latina. A capital materializa as contradições da sua modernidade: ela abriga as grandes instituições políticas, veículos de mídia, restaurantes, bares e

7 Fazemos referência ao título do livro de Carlos Rincón (v. referência bibliográfica). 
hotéis, numa circulação caótica de pessoas - mas nela o narrador testemunha uma tentativa de golpe de estado, na rotina de violência que caracteriza a vida política do país. Fora dali, em meio à paisagem bucólica - mas dela seguramente protegida -, está a vila pitoresca (Guanajuato, Cuzco, Ouro Preto...), tomada por turistas e artistas: o pitoresco protege contra o país real oferecendo dele uma versão domesticada, que atrai o falso aventureiro estrangeiro e o nativo europeizado (que se ocidentaliza como forma de autodistinção); ali, o narrador testemunha a condescendência do gringo pelo país e a subserviência do intelectual nativo (em sua emulação dos modelos do Centro), ambos contrastados, pela codificação dos seus pequenos hábitos e opiniões, com a maior espontaneidade e vitalidade do nativo local. Este contraste, por sinal, gera conflitos entre o narrador e a sua amante americana, que prefere permanecer no vilarejo: naquele espaço controlado ela se sente mais confortável, fugindo do país real e optando pela segurança da sua versão "exótica".

Mais adiante, no limiar da natureza aberta, a cidade à beira do grande rio tem uma infra-estrutura pobre, instalações ainda mais pobres, comunicação e acesso difíceis. O lugar é marcado pelo desmando, pela fraqueza da lei positiva e pela violência da sua "lei natural" - seus códigos de honra e de direito à posse -, orientada por um individualismo econômico agressivo: ali o narrador encontra a modernidade como uma "livre iniciativa" processada, à revelia do Estado, por agentes que constroem a nação "profunda" de maneira alheia aos preceitos da "civilização". É dali que ele parte para subir o rio, onde, por fim, ele encontra a cidade fundada secretamente em meio à selva, o que opera um recuo vertiginoso no tempo - o narrador vivenciando, em pleno século XX, a repetição da fundação da América como invenção do Descobrimento: em meio à selva, ergue-se uma igreja, tal como no gesto original de Cortéz que se repetiria tantas vezes nos séculos seguintes.

Note-se a diferença, portanto: enquanto o Orinoco de Neruda era visto e sentido por um eu lírico cuja experiência do 
contato fazia superar a sua distância inicial do lugar, o Orinoco de Carpentier produzia um choque antropológico vivo, e virtualmente instransponível. Ao invés do eu que subjetivava a América monologicamente, ou que a lia dialogicamente apenas com o recurso a um mito compartilhado, Carpentier encenava a experiência lenta do choque entre a linearidade, a clareza, a imediata legibilidade dos padrões civilizacionais do Norte e o improviso, o casuísmo, o silêncio dos padrões do Sul - que, pouco enunciados ou teorizados, deviam ser percebidos, intuídos, "captados"... Daí a atribuição de "autenticidade" e "verdade" àquele habitus cultural, compartilhado através de pressupostos nem sempre articulados - em contraste com a positividade, a normatividade, a segurança e a frequente "artificialidade" do habitus do Norte. Para a apreensão desta diferença, ao invés da interiorização do lugar pela experiência estético-sensorial ou pela intelectualização distanciada, tem-se o seu processamento lento por um observador lançado a um universo que ele não controla interpretativamente, numa experiência etnológica dificilmente poetizável na temporalidade curta da lírica, e mais propriamente narrada como um processo de aprendizado. Tal como num "romance de formação", a viagem àquele Sul nem antigo nem moderno transformaria o narrador intimamente ao produzir, nele, uma apercepção da diferença cultural - mesmo que ela fosse mais claramente apreendida pelo leitor do que pelo próprio personagem, como ficaria claro em seu desfecho final.

Tais diferenças não eliminam, porém, que a valorização positiva do Sul sugerida por esta mobilização da dicotomia revelasse, como em Neruda, certa permanência do mito, agora sob uma roupagem antropológica. Os quatro lugares visitados pelo narrador são observados a partir de um quinto lugar: a metrópole do Norte, cujos padrões culturais o narrador absorvera. A questão permanece: não estaria Os passos perdidos sintetizando a identidade latino-americana ao contrapor a sua fratura interna a uma unidade cultural contraposta? É certo que a unificação era parcial; além do mais, naquele limiar entre a modernidade e a 
porção "encantada" onde a organicidade cultural do continente estava preservada, a idealização se deparava com a impossibilidade da conciliação. Após um interlúdio no Norte, o narrador, que afinal decidira se integrar definitivamente ao Sul, não encontraria, após o seu período de ausência, aquilo que voltara para resgatar: a cidade recém-fundada, a mulher com quem ele havia se unido e as pessoas que o levaram para o alto do rio. Após um breve período nada havia a retomar, pois nada que ele vivera havia se perenizado: as pessoas sequer estavam lá; de volta ao Sul, ele era novamente um estrangeiro. Não haveria conciliação: em relação ao Sul "profundo", o seu distanciamento não seria superado; naquele fruto da Conquista insularizado num território ermo e nãointegrado, a sua capacidade de compreensão se revelara insuficiente e, sem qualquer síntese final que convergisse a diferença em unidade, a sua experiência terminaria em aberto.

Mas toda esta leitura do Sul, em sua multiplicidade interna, era unificada pela perspectiva do Centro. Historicamente, a dicotomia operara negativamente: somos aquilo que eles não são - não somos ricos, não somos instruídos, não somos institucionalmente avançados, não somos socialmente justos... Em compensação, com frequência nossa cultura autóctone era lida com sinais positivos: ela seria orgânica, autêntica, "encantada"... Em Ospassos perdidos, noções como estas perpassavam os conflitos entre o narrador e certos tipos representativos do Centro - a sua esposa e a sua amante, jornalistas, pessoas do Norte que ele encontra no Sul, nativos do Sul que imitam o habitus do Norte... -, num equacionamento da dicotomia identitária que ecoava, em linhas gerais, a ideologização das diferenças culturais entre o Sul e o Centro que se convencionou chamar de "iberismo":

O iberismo pode ser entendido, negativamente, como a recusa de aspectos centrais do [...] mundo moderno. É a negação da sociedade utilitária individualista, da política contratualista, do mercado como ordenador das relações econômicas. Positivamente, é um ideal de sociedade 
fundado na cooperação, na incorporação, no predomínio do interesse coletivo sobre o individual, na regulação das forças sociais em função de um objetivo comunitário. (Carvalho, 2005, 214)

Tal ideologização transparece em Os passos perdidos, mesmo que o Sul não seja visto com simpatia irrestrita e que o narrador, incapaz de transpor a barreira cultural, não ofereça ao leitor um fundamento, retirado da simpatia pelo lugar, que apoiasse programaticamente a imaginação do seu futuro e da sua autoprodução social (à diferença de Neruda). Ao final de Os passos perdidos, nada está resolvido: de maneiras diferentes, o narrador traíra a sua esposa americana (de quem ele não se divorciara), a sua amante americana (que o acompanhara ao Sul) e a nativa por quem ele se apaixonara (e que ele havia desposado, sem compreendê-lo plenamente, durante a expedição à selva). Ele traíra de maneiras diferentes aquelas três mulheres diferentes: a sua esposa (que tipificava a vida mediana e o contratualismo moderno), a sua amante (que tipificava a boemia artística e intelectual do Norte, padrão convencional de transgressão do estilo de vida simbolizado pela sua esposa), e a sua amante nativa (cujo silêncio sobre as suas expectativas em relação a ele o havia levado a uma união não verbalizada, mas ainda assim estável pelas expectativas locais). Invertendo, pois, a projeção oitocentista do enlace amoroso como remissão à possibilidade da conciliação identitária - conforme a análise de Doris Sommer -, em Os passos perdidos o narrador trai as duas versões majoritárias da cultura do Norte e a cultura que ele pensara haver adotado no Sul: ao trair a sua esposa, ele trai a lei positiva do Centro (o seu vetor civilizatório); ao trair a sua amante, ele trai a cultura desviante do Centro (a resposta que o próprio Centro oferece à clausura da sua civilização); ao trair Rosario, ele trai a lei orgânica do Sul. Traidor, ele é reciprocamente rejeitado pelas três leis que aquelas mulheres representavam: ele tanto se aliena da "direita" e da "esquerda" do Centro, quanto se mostra incapaz de compreender 
a alternativa do Sul. De volta ao Orinoco, ao final do seu aprendizado ele descobre que ele nada havia aprendido: tarde demais para harmonizar o seu passado recente e o seu futuro imediato, a sua compreensão da sua trajetória emerge como um desvelamento doloroso:

A verdade, a angustiante verdade - compreendo agora é que as pessoas destas lonjuras nunca acreditaram em mim. Fui um ser emprestado. A própria Rosário deve ter me visto como um Visitador, incapaz de permanecer indefinidamente do Vale do Tempo Detido. [...] Os novos mundos têm que ser vividos, mais do que explicados. Aqueles que aqui vivem não o fazem por convicção intelectual; acreditam, simplesmente, que a vida suportável é esta e não a outra. Preferem este presente ao presente dos fazedores do Apocalipse. O que se esforça para compreender muito, o que sofre as aflições de uma conversão, o que pode alimentar uma ideia de renúncia ao abraçar os costumes daqueles que forjam seus destinos sobre este pântano original, em luta travada com as montanhas e as árvores, é homem vulnerável porque certas potências do mundo que deixou para trás continuam atuando sobre ele. Viajei através das idades; passei através dos corpos e dos tempos dos corpos, sem ter consciência de que havia deparado com a recôndita estreiteza da mais ampla porta. [...] Tratei de endireitar um destino torcido por minha própria debilidade e de mim brotou um canto - agora truncado-que me devolveu ao velho caminho, com o corpo cheio de cinzas, incapaz de ser outra vez o que fui. (CARPENTIER, 2009, p. 296-297)

O Sul coloca em suspenso o poder interpretativo do observador do Norte, como mais tarde seria hiperbolizado no René Descartes do Catatau de Paulo Leminski ou no McLubanaíma de Richard Morse - McLuhanaíma, o fictício brasilianista norteamericano que, no Brasil, "[r]apidamente se vê às voltas com um mundo em que suas teorias não funcionam, em que o mitológico e o fantástico ainda afetam a vida das pessoas. Diante disto, seus 
métodos de pesquisa se revelam impotentes, se não ridículos." (Carvalho, 2005, 402) Tal equacionamento cristaliza a alteridade da América Latina diante do Centro: se o Sul é indecifrável, a consciência desta impenetrabilidade demarca a sua unidade diante do olhar estrangeiro. Em Carpentier, decerto este olhar é complexificado: fracassado, o narrador deixa de se iludir quanto à sua própria capacidade de compreensão, e assim o Sul deixa de ser sintetizável monologicamente porque o próprio Centro deixava de sê-lo - que a segurança do olhar do Centro faltasse a si mesma, isso sugeria que a sua unidade também era um mito (fraturando, de roldão, a epistemologia romântica da sensibilidade como acesso imediato - e modo de conhecimento verdadeiro - da realidade exterior). Mas mesmo que com contornos difusos, as duas velhas unidades culturais eram colocadas em contraste, o Sul sendo mais uma vez definido, negativamente, à diferença do Norte. Sintoma disso é que a ignorância fundamental do narrador não eliminava que pouco espaço era aberto para que o Sul interpretasse a si mesmo: na permanente mediação do olhar externo, o Sul seguia desprovido de autoteorização, fazendo com que a diferença de Carpentier em relação à tradição latino-americana não estivesse na suspensão da dicotomia, mas no tensionamento que impedia o seu prolongamento inquestionado: tensionada internamente, a dicotomia passava a apresentar limites discerníveis, sugestivos de uma exaustão que se começava a entrever.

\section{Suma}

Se é plausível identificar a emergência de uma literatura latino-americana "pós-mito", "pós-identidade" ou mesmo "pós'latino-americana", o caminho para a sua análise foi aberto pela geração de críticos que, a partir dos anos 80 - com Echevarría, Sommer, Martin...-, desnaturalizou o paradigma nacionalista que fundara as literaturas latino-americanas no século XIX e que seguiria, no século XX, fomentando a representação da paisagem 
natural e social como meio de afirmação de identidades regionais, nacionais ou continentais. Hoje, quando o próprio conceito de "literatura nacional" perde importância, a pesquisa identitária dá lugar a uma "literatura global" aberta a uma multiplicidade de códigos disseminados transnacionalmente - e a porção latinoamericana desta literatura global não mais apresenta orientações dominantes que a unifiquem. O seu olhar sobre o continente revela um novo tipo de sensibilidade, renovado em seu componente endógeno e em suas pretensões ao universalismo: quando endógeno, ele não é costumbrista, não mais identificando nos hábitos e paisagens a especificidade da cultura; em seu apelo global, ele tematiza a experiência essencialmente moderna vivida no continente. Por ora, ainda é difícil explicar a radicação social desta nova sensibilidade. Acreditamos, porém, que ela se manifesta plenamente em Roberto Bolaño, cuja obra fomenta uma releitura da história do romance latino-americano que nos sensibiliza, hoje, para a identificação de uma inflexão da problemática identitária já em Carpentier, que mitigava, talvez contra o seu próprio projeto, a centralidade (ou a própria possibilidade) do mito como meio de conhecimento do continente. Em Carpentier, o tratamento das relações interculturais como um ato interpretativo fragilizava dois dos suportes centrais do acordo proposto por Neruda: a legitimação romântica da experiência íntima como meio de acesso à verdade (i.e. a dimensão epistemológica da sua representação da paisagem) e a segurança dos seus parâmetros valorativos (a dimensão política do seu recurso ao mito). Restava apenas a crítica dicotômica à Modernidade, cristalizada na oposição Sul-Centro: nela sobrevivia, em Carpentier, a lógica operatória do mito, que afinal seria, décadas mais tarde, rasurada em 2666.

Pois naquele romance Bolaño observava a América Latina sem recorrer a mitos, a autoelogios, à autocomiseração ou à autodepreciação: livre destes modos convencionais de equacionamento da experiência do continente, posicionando-se entre a endogenia e a onisciência, ele renovava, um tanto ironicamente, as pretensões à objetividade características de boa 
parte do romance latino-americano - manifestando a pretensão implícita a um realismo que estivesse finalmente depurado da mitificação e do reducionismo ideológico. Vista por este ângulo, a sua obra renovava as pretensões à representação coerente da realidade local ao combater as formas de idealização historicamente subjacentes a ela (como fora o caso do "realismo mágico", em seu sucesso internacional a partir dos anos 60). Com esta diferença, fechava-se um círculo histórico do romance latinoamericano - que procuramos reconstituir, em sobrevôo, ao situarmos Carpentier entre Neruda e Bolaño.

\section{REFERÊNCIAS}

BASTOS, A. R. Yo el Supremo. Buenos Aires: Siglo Veintiuno Editores, 1974.

BLOOM, H. Walt Whitman como centro do Cânone Americano. In: . O cânone ocidental. Rio de Janeiro: Objetiva, 1995, p. 256-282.

BOLAÑO, R. 2666. São Paulo: Companhia das Letras, 2010.

CARPENTIER, A. Os passos perdidos. São Paulo: Martins Fontes, 2009. CARVALHO, J. M. de. A utopia de Oliveira Viana. In: . Pontos $e$ bordados. Escritos de história e política. Belo Horizonte: Editora UFMG, 2005, p. 202-31.

CARVALHO, J. M. de. Richard Morse e a América Latina: ser ou não ser. In: Pontos e bordados. Escritos de história e política. Belo Horizonte: Editora UFMG, 2005, p. 400-8.

CORTÁZAR, J. O jogo da amarelinha. São Paulo: Círculo do Livro, 1987.

ECHEVARRÍA, R. G. Mito y archivo: Una teoría de la narrativa latinoamericana. Cidade do México: Fondo de Cultura Económica, 2000.

GUMBRECHT, H. U. Lento presente. Sintomatología del nuevo tiempo histórico. Madri: Escolar y Mayo, 2010.

LEMINSKI, P. Catatau. Porto Alegre: Sulina, 1989.

LIMA, L. C. O controle do imaginário. Rio de Janeiro: Forense Universitária, 1983. 
MARTIN, G. Journeys through the labyrinth. Latin American fiction in the Twentieth Century. New York: Verso, 1989.

MARTIN, G. The novel of a continent: Latin America. In:

MORETTI, F. (Org.). The Novel, Vol. 1. Princeton: Princeton University Press, 2006, p. 632-667.

MORSE, R. M. A volta de McLubanaíma. Cinco estudos solenes e uma brincadeira séria. São Paulo: Companhia das Letras, 1990.

NERUDA, P. Canto general. Buenos Aires: Editorial Losada, 1996.

RENÉ-MORENO, G. Poesia e política na América. In: . ACÍZELO, R. Uma ideia moderna de literatura. Textos seminais para os Estudos Literários (1688-1922). Chapecó, Argos, 2011, p. 210-218.

RINCÓN, C. La no simultaneidad de lo simultáneo: postmodernidad, globalización y culturas en América Latina. Santafé de Bogotá: Editorial Universidad Nacional, 1995.

ROUANET, M. H. Eternamente em berço esplêndido. A fundação de uma literatura nacional. São Paulo: Siciliano, 1991.

SOMMER, D. Ficções de Fundação. Os romances nacionais da América Latina. Belo Horizonte: EdUFMG, 2004.

SÜSSEKIND, F. Tal Brasil, qual romance? Rio de Janeiro: Achiamé, 1984.

VOLPI, J. La nueva narrativa bispánica de América (em más de 100 aforismos, casi tuits). Disponível em: <http://www.nexos.com.mx/?P= leerarticulo\&Article $=2099498>$. Acesso em $28 \mathrm{dez} .2012$.

WHITMAN, W. Folbas de relva. São Paulo: Iluminuras, 2006.

Recebido para publicação em 31 de dezembro de 2012. Aprovado em 5 de maio de 2013. 